\section{UCDNN}

LIBRARY
University of Connecticut OpenCommons@UConn

June 1991

\title{
Stability of Mandibular Incisor Position
}

Jin-Myung Kim

Follow this and additional works at: https://opencommons.uconn.edu/sodm_masters

\section{Recommended Citation}

Kim, Jin-Myung, "Stability of Mandibular Incisor Position" (1991). SoDM Masters Theses. 69.

https://opencommons.uconn.edu/sodm_masters/69 
Dr. Jin-Myung Kim

In Partial Fulfillment of the Requirements of Certificate in Orthodontics

Major Advisor: Dr. Ravindra Nanda

Co-Advisors: Dr. Charles J. Burstone

Dr. Joseph Burleson

Division of Orthodontics

The University of Connecticut Health Center

Farmington, Connecticut 06032

1991 


\title{
APPROVAL PAGE
}

Certificate in Orthodontics Thesis.

The stability of Mandibular Incisor Position

\author{
presented by \\ Dr. Jin-Myung Kim
}

Major Advisor: $\frac{\text { Kaninda }}{\text { Dr. Ravindra Nanda }}$ ande.

co - Advisors : $\frac{C A}{\text { Dr. Charles J.Burstone }}$

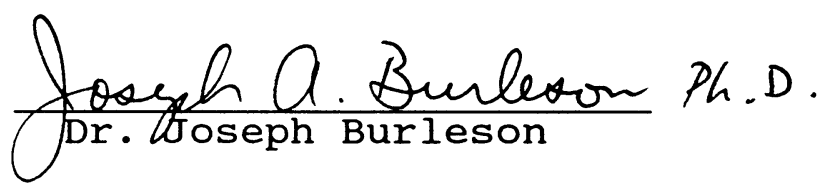

The University of Connecticut Health Center 


\section{ABSTRACT}

This retrospective study was performed to investigate the stability of the mandibular incisor position following orthodontic treatment. Thirty-four patients were selected. Three time periods were studied; pretreatment(T1), post-treatment(T2) and postretention(T3). The changes of dental, hard and soft tissue at T1T2 and T2-T3 were measured using study models and cephalograms. The correlation coefficient between the incisor irregularity at T3 and various pretreatment variables was performed in addition to standard statistical methods. The results of the present study showed a significant increase in incisor irregularity at postretention along with other significant dental and soft tissue changes. The increase in incisor irregularity during postretention phase was found to be correlated with the amount of crowding prior to the treatment, upper and lower lip protrusion at the end of the treatment, the degree of retroinclination of the mandibular incisors at the start of the treatment, and the amount of the mandibular growth. Often mentioned factors such as upper incisor inclination, overbite, arch length, overjet, intermolar and intercanine widths, mandibular rotation and lip thickness and length did not show a correlation with the post-retention mandibular incisor irregularity. The result suggests that treatment mechanics may play a significant role in the stability of the mandibular incisor position. 


\section{INTRODUCTION}

The position of the mandibular incisors has been the focus of numerous clinical reports as they have served as guides for treatment planning and stability of attained results. A number of studies in recent years have investigated the stailitity of the mandibular incisors following orthodontic treatment.

The final position of mandibular incisors following treatment can change due to various causes acting alone or together. Some of the factors reported in the literature are, differential dentofacial growth, patient age and sex, incisor position over the basal bone, tooth size-arch dimension, anterior component of the occlusal force, eruptive force of the third molars, soft tissue and musculature, physiologic recovery, inappropriate mechanics, periodontal fibers, treatment procedures, and the length of retention period. However, the nature of the correlation between the post-treatment changes in the mandibular incisor position and some of the above mentioned predisposing factors is still unclear. 


\section{REVIEW OF THE IITERATURE}

\section{Dental Changes}

A number of long term studies have been conducted to determine the stability of mandibular incisor position in untreated growing individuals. The crowding of the lower incisors increases after the permanent dentition especially between the ages of 14 to 20 years.1,2,3,4 Furthermore, intercanine width increases markedly until canines erupt, and decreases slightly afterwards.4,5 Untreated individuals also show a decrease in arch length during the premolar eruption which thereafter decreases steadily.1,4 Intermolar width also decreases with age, ${ }^{4,6}$ however, Moorrees ${ }^{1}$ reported an increase between the ages of 9 to 14 years.

Post-retention studies of dental changes indicate a different pattern compared to the untreated groups. Little ${ }^{7}$ reported an increase in incisor irregularity in extraction patients at postretention period. Glenn et al. ${ }^{8}$ found relatively stable incisor position in nonextraction post-retention patients as compared to patients who had extractions. However, Uhde et a1.9 reported no different relapse tendencies between extraction and nonextraction patients. Fastlicht ${ }^{10}$ found more crowding in untreated individuals as compared to treated patients.

Mandibular intercanine width generally decreases in both 
extraction and nonextraction patients during post-retention. $7,8,9,11,12$ Intermolar width decreases 9,12 or it remains relatively stable during post-retention. 8,11

Overbite has been shown to increase from mixed dentition to permanent dentition and decreases subsequently during maturation of untreated occlusion.1,4,6 overbite tends to increase slightly during postretention stage both in extraction and nonextraction groups.9.13 However, Glenn et. al. ${ }^{8}$ found overbite remained remarkably stable in nonextraction patients. Little et al. ${ }^{7}$, and Hernande $z^{14}$ have reported a significant relapse of overbite in extraction patients.

\section{Incisor position and adjacent hard tissue variables}

The final tooth position at maturity is influenced by the relative amount and direction of anteroposterior and vertical facial growth. ${ }^{15,16}$ Bjork and Skieller ${ }^{15}$ have indicated that the dentitional changes in tooth position and axial inclination were the result of a balance between the facial, skeletal and dental relationships. Other studies have mentioned following factors; anterior growth of the mandibular base ${ }^{3}$, axial inclination of mandibular incisor relation to mandibular molar inclination ${ }^{17}$, a relationship of mandibular inclination to the maxillary base ${ }^{18}$, downward mandibular growth and forward mandibular rotation 19,20, and a relationship of lower incisor size to the size of the face and 
jaws $^{21}$. A longitudunal investigation ${ }^{22}$ based on the Denver growth study shows relatively constant mandibular incisor angular measurement with age such as the interincisal angle and mandibular incisor to mandibular plane. Sinclair and Little ${ }^{16}$ found that incisor angulation to the cranial base was relatively stable in untreated patients but failed to correlate with lower incisor position and factors relating to growth pattern. Miethke ${ }^{23}$ also indicated no correlation between lower incisor crowding and either skeletal morphology or mandibular incisor position.

In a postretention study using cephalometric variables ElMangoury ${ }^{24}$ found orthodontic relapse associated with a decrease in the palatal plane and mandibular plane angle. Huggins and Birch 25 reported that an early relapse in upper incisor position could cause a new incisal relationship. Shields ${ }^{26}$ and Schulhof ${ }^{27}$ reported no significant correlation between cephalometric variables such as incisor position, facial growth and long-term mandibular irregularity.

\section{Soft tissue factors}

Several studies have shown that the position of lower incisor is influenced by the surrounding musculature. ${ }^{28,29}$ Luffingham ${ }^{30}$, and Thuer and Ingerval $1^{31}$ found that different malocclusion group have different lip and cheek pressure. Riedel ${ }^{32}$ reported that the soft tissue profile is closely related to the skeletal and dental 
structures that comprise the bony profile. Winders ${ }^{33}$ indicated stable tooth position has minimal lingually directed muscle pressure against the incisors. Subtenly $y^{34.35}$ reported that all components of the soft tissue musculature do not directly follow the underlying skeletal profile, although lip posture was found to be closely related with the position of the underlying dental and alveolar structures. Burstone $e^{36,37}$ noted that the postural position of the lower lip influences the maintenance of the original mandibular incisor position. He also mentioned that although tooth stability and facial esthetics are closely related to soft tissue morphology and posture of lips, relaxed postural lip position is partially independent of tooth position.

The lip change during growth is sexually dimorphic. Lenard ${ }^{38}$ showed a slight retrusion of upper and lower lip during growth in males and females. Males showed a larger change in the upper and lower lip length growth whereas females showed only a small change. Upper and lower lip thickness also increased significantly in the male group, but only slightly in the female group. Nanda et al. ${ }^{39}$ agreed with different male and female patterns and added that most of the soft tissue measurements in females had attained their adult size at the age of 15 years, whereas in males, several measurements appeared to be on the increase even at the age of 18 years.

Rudee $^{40}$ reported, the ratio of soft tissue profile response 
concomitant to dental or skeletal changes during treatment. Bloom ${ }^{41}$ also found the possibility of predicting perioral soft tissue changes in relation to the expected amount of anterior tooth movement like lower incisor. However, Burstone ${ }^{37}$ and Hershey ${ }^{42}$ indicated that perioral soft tissues may be self-supporting and that factors other than dental movement may cause the wide variety of individual response. Oliver ${ }^{43}$ also showed that soft tissue may vary enough in thickness, length and postural tone to cause the response of soft tissue to incisor retraction to be different in persons with thick upper lips as compared to those with thin upper lips. Anderson et al. ${ }^{44}$ showed that the upper lip thickness increases considerably following maxillary incisor retraction while the lower lip was not found to be affected by orthodontic treatment. Raines and $\mathrm{Nanda}^{45}$ indicated that the change in mandibular incisor position does not correlate with lip changes, and the lower lip response is influenced by various other factors such as the direction of the growth of the mandible.

\section{OBJECTIVES}

The objective of this retrospective study is to investigate the stability of the mandibular incisor position following orthodontic treatment. The study attempted to establish the correlation between mandibular incisor position and several dental, 
skeletal and soft tissue factors. The dental parameters including anteroposterior and width changes were measured on occlusograms of the study casts. The differences in skeletal and soft tissue values were evaluated by cephalometric measurements.

\section{MATERIALS AND METHODS}

\section{Patient selection}

Thirty-four Caucasian patients treated at the orthodontic clinic of the University of Connecticut Health Center and from the orthodontic practices of two part-time faculty members were selected for the study. The mean age at the start of the treatment was 12.9 years. All patients received edgewise orthodontic therapy. The records were obtained from three time intervals namely, pretreatment (T1), at the end of treatment (T2) and at least one year out of retention (T3). The subjects were further categorized by extraction or nonextraction, sex and Angle's dental classification (Table 1).

\section{Dental Measurements}

Dental casts of different periods were collected and recorded using the occlusograms ${ }^{46}$. The following measurements were analyzed by computer-aided digitizing program (Fig.1) • 
1. Mandibular incisor irregularity index - The sum of displacement of the anatomic contact points of the lower anterior teeth as suggested by Little $e^{47}$.

2. Mandibular intercanine width - The distance between the cusp tips of left and right canine.

3. Mandibular intermolar width - The distance between the central fossae of the left and right first molars.

4. Mandibular arch length - The sum of the distances between the mesial contact point of the first molar and the contact or midpoint of the mandibular central incisors ( Nance $^{48}$ ).

\section{Cephalometric measurements}

Lateral cephalometric headfilms in centric occlusion and with relaxed lips were taken at pretreatment (T1), post-treatment (T2) and at post-retention (T3) periods. Tracings of lateral cephalometric headfilms were analyzed by a computer aided cephalometric analysis program (Fig 2). Lateral tracings were superimposed using anterior cranial base and ethmoid triad structures. An $\mathrm{x}$ - and $\mathrm{y}$-coordinate system was utilized for analyzing horizontal and vertical changes (Fig 2). A horizontal (x) reference line was used as Constructed Frankfort Horizontal line $\left(\mathrm{CFH}, \mathrm{SN}-7^{\circ}\right)$. A perpendicular line to $\mathrm{CFH}$ drawn at point sella served as the vertical reference line $(y)$.

Maxillary superimpostion based on the zygomatic process, inferior orbital rim and suborbital structures was used to examine 
the maxillary dental changes. Changes are also noted using nasal floor (NF) as $x^{\prime}$-coordinate and a perpendicular line to NF served as the $y^{\prime}$-coordinate (Fig 2).

Mandibular superimposition was based on the inner structures of the symphysis, cortical outlines of the anterior mandibular body and the mandibular canal. Original plane of occlusion was also used as $x^{\prime \prime-c o o r d i n a t e ~ a n d ~ p e r p e n d i c u l a r ~ l i n e ~ o f ~ o P ~ w a s ~ u s e d ~ a s ~ t h e ~}$ $y^{\prime \prime}-$ coordinate (Fig 2).

Three types of changes between T1-T2 and T2-T3 were recorded, a. absolute change

b. positive change - anterior or extrusive change c. negative change - posterior or intrusive change

The following 20 linear and 11 angular measurements were used for cephalometric analysis(Fig.2):

\section{Mandibular Incisor Measurements}

1. L1-CFH $\left({ }^{\circ}\right)$ : The angle between axial inclination of mandibular central incisor(L1) and Conctructed Frankfort Horizontal(CFH) . 2. L1-MP $\left({ }^{\circ}\right)$ :The angle between axial inclination of mandibular central incisor and mandibular plane(Go-Me).

3. L1-OP $\left({ }^{\circ}\right)$ : The angle between axial inclination of mandibular 
central incisor and occlusal plane.

4. L6-OP $\left({ }^{\circ}\right)$ : The angle between axial inclination of mandibular first molar(L6) and occlusal plane.

5. Ii-CFH(mm,y-coordinate): The perpendicular distance between mandibular central incisal edge and $\mathrm{CFH}$.

6. Ii-CFH(mm, $x$-coordinate): The perpendicular distance between mandibular central incisal edge and perpendicular line of CFH. 7. Ii-OP (mm, $\mathrm{Y}^{\prime \prime}$-coordinate): The perpendicular distance between mandibular central incisal edge and occlusal plane.

8. Ii-OP(mm, $x^{\prime \prime-c o o r d i n a t e): ~ T h e ~ p e r p e n d i c u l a r ~ d i s t a n c e ~ b e t w e e n ~}$ mandibular central incisal edge and perpendicular line of occlusal plane.

Maxillary Incisor Measurements

9. $\mathrm{U} 1-\mathrm{CFH}\left({ }^{\circ}\right)$ : The angle between axial inclination of maxillary central incisor(U1) and $\mathrm{CFH}$.

10. $\mathrm{U} 1-\mathrm{NF}\left({ }^{\circ}\right)$ : The angle between axial inclination of maxillary central incisor and nasal floor(ANS-PNS).

11. U1-LI $\left({ }^{\circ}\right):$ The angle between axial inclinations of maxillary and mandibular incisor.

12. U1-L1 (CFH, mm, overjet): The horizontal distance between maxillary and mandibular central incisal edges parallel to CFH.

13. U1-L1 ( $\mathrm{CFH}, \mathrm{mm}$, overbite): The vertical distance between maxillary and mandibular central incisal edges perpendicular to $\mathrm{CFH}$.

14. U1-CFH(mm,Y-coordinate): The perpendicular distance between maxillary central incisal edge and $\mathrm{CFH}$. 
15. U1-CFH(mm, $\mathrm{x}$-coordinate): The perpendicular distance between maxillary central incisal edge and perpendicular line of $\mathrm{CFH}$. 16. U1-NF(mm, $\mathrm{Y}^{\prime}$-coordinate):The perpendicular distance between maxillary central incisal edge and nasal floor.

17. $\mathrm{U} 1-\mathrm{NF}\left(\mathrm{mm}, \mathrm{x}^{\prime}\right.$-coordinate): The perpendicular distance between maxillary central incisal edge and perpendicular line of $\mathrm{NF}$

\section{Soft Tissue Measurements}

18. Pls(Sn-Pg', mm, upper lip protrusion): The perpendicular distance from most anterior part of upper lip(Prolabale superius, Pls) to sbnasale(Sn)-soft tissue pogonion(Pg') line.

19. Pli(Sn-Pg', mm, lower lip protrusion): The perpendicular distance from most anterior part of lower lip(Prolabale inferius, Pli) to SnPg'.

20.Cm-Sn-Pls(nasolabial angel): The angle formed by a line connecting columella $(\mathrm{Cm})-\mathrm{Sn}$ to the line from Sn-Pls.

21. Upper lip thickness $(\mathrm{CFH}, \mathrm{mm})$ : The horizontal line from $\mathrm{A}$ point to Sn parallel to $\mathrm{CFH}$.

22. Lower lip thickness $(\mathrm{CFH}, \mathrm{mm})$ : The horizontal distance from Pli to contact point between labial surface of mandibular central incisor and inner margin of lower lip parallel to $\mathrm{CFH}$.

23. Upper lip length $(\mathrm{CFH}, \mathrm{mm}):$ The vertical distance from $\mathrm{Sn}$ to lower most point of upper lip(Stms) perpendicular to $\mathrm{CFH}$.

24. Lower lip length $(\mathrm{CFH}, \mathrm{mm})$ : The vertical distance from upper most point of lower lip(Stmi) to mentolabial sulcus(Mls) perpendicular to $\mathrm{CFH}$. 
25. Lip to tooth contact $(\mathrm{mm})$ : The distance from mandibular incisal edge to contact point between labial surface of mandibular central incisor and inner margin of lower lip.

\section{Occlusal Plane Measurements}

26. $\mathrm{A}-\mathrm{B}(\mathrm{OP}, \mathrm{mm})$ : The distance between perpendicular line from $\mathrm{A}$ and B point to occlusal plane.

27. OP-CFH $\left({ }^{\circ}\right)$ : The angle between occlusal plane and CFH.

\section{Mandibular Rotation Measurements}

28. Y-axis $\left({ }^{\circ}\right)$ :The angle between $\mathrm{CFH}$ and the sella-gnathion(Gn) line.

29. Ar-Go-Me(gonial angle): The angle between articulare(Ar)gonion(Go) and Go-menton(Me) line.

\section{Growth Measurements}

30. $\operatorname{Ar}-\mathrm{Pg}(\mathrm{mm})$ : The distance between Ar and Pg.

31. ANS-Me(mm): The distance between ANS and Me.

\section{statistical Analysis and Measurement Reliability}

Statistical analyses were performed by standard methods. Mean and standard deviation were calculated for each variable at $\mathrm{T} 1$, T1-T2, and T2-T3. Paired t-test was performed for assessing significance of the change from $\mathrm{T} 1$ to $\mathrm{T} 2$, and from $\mathrm{T} 2$ to $\mathrm{T} 3$. Pearson correlation coefficient analysis was used to analyze the 
relationship between the changes at $\mathrm{T} 1-\mathrm{T} 2$ with those at $\mathrm{T} 2-\mathrm{T} 3$ to estimate the effects of treatment magnitude to relapse. Pearson correlation coefficients were also calculated between the changes in incisor irregularity at $\mathrm{T} 2-\mathrm{T} 3$ and absolute, positive and negative changes at $\mathrm{T} 1-\mathrm{T} 2$ and $\mathrm{T} 2-\mathrm{T} 3$, respectively.

student $t$-tests were used for assessing the significant differences between extraction and nonextraction, males and females, Angle dental classification Class I and Class II, respectively.

To assess the reliability of measurements in tracing and digitizing procedures, five cephalograms and occlusograms were randomly selected. Five angular and five linear measurements were selected from original tracing, and were compared with each other using Pearson correlation coefficient. The average correlation coefficient was $r=0.85(p<0.01)$ in linear measurements and $r=$ $0.95(p<0.005)$ in angular measurements. For the digitizing error all dental measurements and five linear and five angular measurements were redigitized and compared to original data. The average Pearson correlation coefficient was $r=0.91(p<0.001)$. All measurement reliability analyses in the present study indicated high accuracy. 


\section{RESULTS}

\section{Dental Changes}

There was a significant decrease in the incisor irregularity during treatment $(X=-5.30 \mathrm{~mm}, p<0.01)$, which increased during the post-retention period $(X=1.7 \mathrm{~mm}, p<0.01)$. Intermolar width decreased significantly in extraction patients $(X=-2.20, p<0.01)$, whereas nonextraction patients maintained their width during treatment. Both groups remained stable during the post-retention period. There was an increase in the intercanine width during treatment $(X=0.69 \mathrm{~mm}, p<0.01)$ which decreased slightly at $T 3$ ( $X=$ $0.4 \mathrm{~mm}, p<0.01)$. Arch length decreased significantly in extraction patients but remained relatively unchanged in nonextraction patients at $\mathrm{T} 2$. It also showed a further decrease at $\mathrm{T} 3$ although the difference between extraction and nonextraction patients was not significant(Table II).

\section{Mandibular Incisal Position}

Angular measurements showed no significant changes in both treatment and post-retention period except for the first molar uprighted in relation to the occlusal plane angle. In the linear measurements, extrusion of the incisal edge of the mandibular incisor was significant at $\mathrm{T} 2(\mathrm{X}=-1.81 \mathrm{~mm}, p<0.01)$ and it moved further superiorly at T3 $(X=-0.81 \mathrm{~mm}, p<0.01)$. Mandibular incisor also moved superiorly relative to the occlusal plane both at T2(X= $1.36 \mathrm{~mm}, p<0.01)$ and $\mathrm{T} 3$ periods $(X=0.81 \mathrm{~mm}, p<0.01)$. Anteroposterior 
changes were not significant in both $\mathrm{T} 1-\mathrm{T} 2$ and $\mathrm{T} 2-\mathrm{T} 3$ period. There was a significant difference between extraction and nonextraction patients $(p<0.01)$ in horizontal movement of mandibular incisors at T2, but no significant difference was found at T3(Table II).

\section{Maxillary incisor position}

Mean maxillary incisor position did not change significantly in the anteroposterior direction at $\mathrm{T} 2$ but did change in anterior direction at postretention period $\left(\mathrm{X}=2.27^{\circ}\right.$ to $\mathrm{CFH}, p<0.05, \mathrm{X}=1.72^{\circ}$ to $\mathrm{NF}, p<0.05$,$) . Overjet decreased significantly during treatment$ $(\mathrm{X}=-1.14 \mathrm{~mm}, p<0.01)$ but increased during postretention period $(\mathrm{X}=$ $0.54 \mathrm{~mm}, p<0.01)$. Overbite decreased during treatment $(X=-0.79 \mathrm{~mm}$, $p<0.05)$ but remained stable during the post-retention period. Vertical position of the maxillary incisor showed a significant downward movement $(\mathrm{X}=1.69 \mathrm{~mm}$ to $\mathrm{CFH}, p<0.01, \mathrm{X}=1.14 \mathrm{~mm}$ to $\mathrm{NF}, p<0.01)$ at $\mathrm{T} 2$ and continued to move downward at $\mathrm{T} 3(\mathrm{X}=1.30 \mathrm{~mm}$ to $\mathrm{CFH}, p<0.01, \mathrm{X}=1.14 \mathrm{~mm}$ to NF, $p<0.01$ ) (Table II).

\section{soft Tissue}

A significant decrease in upper and lower lip protrusion was found during the treatment period (Ls:X= $-1.20 \mathrm{~mm}, p<0.01, \mathrm{Li}: \mathrm{X}=-$ $1.22 \mathrm{~mm}, p<0.01)$. Upper lip remained stable whexeas the lower lip protrusion continued to decrease during the post-retention period. $(X=-0.50 \mathrm{~mm}, p<0.05)$ (Table III). Nasolabial angle $(X=$ $\left.3.55^{\circ}, p<0.01\right)$ and upper lip thickness ( $\left.X=0.70 \mathrm{~mm}, p<0.05 \mathrm{~mm}\right)$ increased significantly at $T 2$, but remained stable during the 
post-retention period. Upper and lower lip length increased signficantly at T2, however, only the lower lip length showed an increase at T3. Lip to tooth contact measured from the incisal edge to the inner lower margin of the lower lip decreased slightly during treatment $(X=-0.99 \mathrm{~mm}, p<0.05)$ but remained stable during the postretention period. Upper lip length, lip thickness, lower lip protrusion, lip to tooth contact showed significant differences between extraction and nonextraction at $\mathrm{T} 2$, whereas no differences were found at T3(Table III).

\section{Occlusal Plane}

No significant changes of the denture base relationship and occlusal plane were found in both $\mathrm{T} 2$ and $\mathrm{T} 3$ observation period (Table III).

\section{Mandibular rotation and growth}

Y-axis decreased slightly during the postretention period $\left(\mathrm{X}=-0.50^{\circ}, p<0.01\right)$. Gonial angle also decreased a small amount at both T2 $\left(X=-0.93^{\circ}, p<0.01\right)$ and T3 periods $\left(X=-1.06^{\circ}, p<0.01\right)$. significant growth of the mandible and lower facial height was found between T1-T2 and T2-T3 periods (Table III).

\section{Interparameter correlations}

The following correlations were studied(Table IV-VI).

1. Correlation between treatment effects (T1-T2) and post-retention changes (T2-T3). 
Maxillary and mandibular incisors, and soft tissue changes during treatment show a significant negative correlation with postretention change, indicating that dental and soft tissues have a tendency to return to their pretreatment position. The angular change of lower incisors correlated with its rebound after treatment. Similarly anteroposterior movements of mandibular incisor also had a correlation, whereas vertical change did not affect any relapse tendency. Maxillary incisor position including overjet had a negative correlation with its post-retention change, and overbite represented a weak correlation. Lip protrusion and thickness showed a tendency to return to pretreatment position. However, lip length did not show a significant correlation with the post-retention changes(Table IV).

2. Correlation between pretreatment variables and the changes in incisor irregularity at post-retention

Table V and VI show the relationship between the postretention changes of mandibular incisors and the pretreatment measurements. Pretreatment incisor crowding, interincisal angle, overjet, lower lip protrusion were not significantly correlated with the post-retention change in incisor irregularity. Axial inclination of mandibular incisors before treatment correlated with post-retention change of incisor irregularity.

3. Correlation between post-treatment(T1-T2), post-retention change (T2-T3) and the changes of incisor irregularity at 


\section{post-retention}

The retroinclination of mandibular incisors at T3 showed a correlation with an increase in incisor irregularity. Extrusion of the mandibular incisor and an increase in overbite also showed a weak correlation with incisor crowing at T3. Increases in upper and lower lip protrusion including nasolabial angle at T2 were found to be correlated with incisor irregularity at T3. The amount of mandibular and lower facial height growth also affected mandibular incisor crowding at post-retention(Tables V and VI). 


\section{DISCUSSION}

In the present study, incisor irregularity was significantly increased at the post-retention period. The amount of incisor retraction and post-retention crowding showed a positive correlation. Little et $a .^{7}$ reported a considerable increase of incisor irregularity in sixty-five patients who had four first premolar extractions. Glenn et $a .^{8}$ showed that the amount of relapse in nonextraction patients was less than the extraction patients and more than untreated normals in a eight year postretention study. Although the present study had a relatively short observation period, there was no significant difference between the extraction and non-extraction patients. Uhde et al. ${ }^{9}$ examined post-retention stability with 20 years post-treatment and reported similar findings.

Mandibular intermolar width decreased relatively more in the extraction patients after treatment, and it remained unchanged during the post-retention period. Shapiro ${ }^{12}$, also reported that the intermolar width decreased at $\mathrm{T} 2$ in the extraction group but a decrease was also noted at T3. Nonextraction patients showed a stable intermolar width at $\mathrm{T} 2$ and $\mathrm{T} 3 .{ }^{8,12}$ Gardner and Chaconas ${ }^{11}$ also reported minimal post-retention change in the intermolar width regardless of the type of treatment. The small differences noted in the above mentioned studies may be due to the method of measuring intermolar width. For example, shapiro ${ }^{12}$ used the tip of 
mesiobuccal cusp, Gardner and Chaconas ${ }^{11}$ measured it from the buccal groove, and the present study used the central fossa of the molar. The method used in the present study was not influenced by the rotational changes of the molars.

Intercanine width showed a slight increase during treatment and it significantly decreased during the post-retention period. Lombardi ${ }^{49}$ reported that the crowding of the mandibular incisors occured with an increase in the mandibular intercanine width during the post-retention period. On the other hand, Little et al. ${ }^{7}$ reported that intercanine width change during T1-T2 and T2-T3 was a poor predictor of long-term crowding. Similarly, the degree of expansion or constriction had little association with the postretention incisor alignment. In this study, intercanine width change was not found to be correlated with an increase in incisor irregularity during post-retention. The results support the observation of Little et $a .^{7}$

Mandibular arch length also decreased significantly at T3. There were no significant differences at the post-retention period between the extraction and non-extraction groups even though considerable more reduction was found in extraction patients. These findings are consistent with those of other studies. $7,8,9,11,12$

The axial inclination and anteroposterior position of mandibular incisor was found to be stable at post-retention. This 
finding is important since it shows that the incisor position was in harmony with the soft tissues at the end of the treatment. ${ }^{28}$ Since the irregularity of mandibular incisors increased significantly during post-retention, it also indicates that axial inclination of the lower incisor is not one of the causative factors. These results support the observation of Shields et al. ${ }^{26}$ and Schulhof et al..27 The present study did show a positive correlation between the amount of flaring done during the treatment to correct retrusive incisors and an increase in crowding at the post-retention phase.

In the present study, maxillary incisor inclination and anteroposterior position changed significantly in the anterior direction during the post-retention period. This supports the observation of Huggins and $\mathrm{Birch}^{25}$ who studied eighty-two patients, up to three years after treatment. On the other hand, Shields et. al. ${ }^{26}$ reported that the upper incisors remained relatively stable ten years post-retention. In the latter study, a significant incisor uprighting was accomplished during treatment.

A majority of the studies have shown that the overbite increases during the retention period. The present study found that there was no significant change at post-retention, although overbite changed significantly during treatment. Since the average post-retention period occurred during adolescence, vertical growth of the mandible and the stability of the intruded teeth might have 
been contributing factors. This study also could not find significant differences in the relapse of the overbite whether extraction was performed or not. These results support the findings of Uhde et al.9, Simons and Joondeph ${ }^{13}$, and Magill ${ }^{50}$. The relationship between the overbite change and incisor irregularity during the post-retention showed weak correlations, supporting the finding of Little et $a .^{7}$

Soft tissues of the face play a major role in the stability of upper and lower incisors in both untreated and orthodontically treated individuals. ${ }^{35,37,44}$ Proffit $^{29}$ concluded that pressure of tongue and lips, as well as the forces created within the periodontal membrane are the primary factors in attainment of dental equilibrium. This has been supported by other studies. $28,30,31$ orthodontic treatment in majority of the patients significantly alters, though temporarily, the soft tissue-hard tissue equilibrium especially due to retraction or flaring of the incisors, expansion or constriction of the arches and shortening or lengthening of the arch length.

In the present study significant observations were made regarding the status of upper and lower lips at the end of the treatment and at the post-retention phase. Upper lip length increased at $\mathrm{T} 2$ and remained stable thereafter. The lower lip length, however, continued to increase into T3 period although less than T2 period. These changes can be attributed to a combination 
of incisor retraction and normal growth. Nanda et al. 39 in a recent longitudinal study on untreated individuals have shown a significant lengthening of the upper $(X=2.7 \mathrm{~mm}$ in males; $X=1.1 \mathrm{~mm}$ in females) and lower $\operatorname{lip}(X=4.2 \mathrm{~mm}$ in males; $X=1.5 \mathrm{~mm}$ in females $)$ between the ages of 7 to 18 years.

The thickness of the upper and lower lip showed a different pattern of change than the length. The upper lip thickened ( $\mathrm{X}=$ $0.70 \mathrm{~mm}$ ) at the end of the treatment, and thereafter, almost no change took place. The lower lip, on the other hand, did not show any appreciable change in thickness at both $\mathrm{T} 1-\mathrm{T} 2$ and $\mathrm{T} 2-\mathrm{T} 3$ observation periods. These results support the observations of Angelle. ${ }^{51}$ Our findings do not support the finding of Anderson et al. 44 who noted continued thickening of the upper lip during postretention. This difference can be explained due to a much longer retention period(10 years) in their study. Similarly, the present results as well as the findings of Anderson et al.44, Angelle ${ }^{51}$ and Ricketts ${ }^{52}$ do not support the finding of Roos ${ }^{53}$ who noted a decrease in the lower lip thickness following treatment. This difference in results is probably due to inclusion of only class II division 1 patients in Roos' study as well as his measurement technique which was differnt.

The relationship of soft tissue measurements with dental changes showed an overall weak correlation except a relatively higher correlation for the upper and lower lip protrusion at the 
end of the treatment. This indicated that if the lips are more protrusive at the end of the treatment, more incisor crowding can be expected at post-retention.

The occlusal plane was stable during the post-treatment and post-retention period. This does not support the results of simons and Joondeph ${ }^{13}$ who reported an increase in the occlusal plane angle at the end of the orthodontic treatment. This difference is probably due to the use of Class II elastics and resultant elevation of the posterior teeth in their studies. The use of Class II elastics was none or minimal in the present study. The overbite correction was performed by the use of incisor intrusion arches $^{54}$ rather than extrusive mechanics.

The correlation of the mandibular growth and incisor irregularity was also studied for various measurements. The direction of the mandibular growth as noted from gonial angle and Y-axis did not show any correlation with the incisor irregularity at the post-retention phase. These results support Lundstrom ${ }^{3}$, Sinclair and Little $e^{16}$ and Solow ${ }^{55}$. However, the amount of mandibular growth of patients in the present study showed a positive correlation with the incisor crowding. This observation suggests that patients with large amount of mandibular growth during posttreatment would also exhibit an increased amount of incisor crowding. 


\section{SUMMARY}

The present study showed that mandibular incisor irregularity increased following the removal of retaining devices. Various parameters reported to be associated with the mandibular crowding were studied, and correlations, if any, were sought. No single causative factor could be determined. The results suggest that the amount of crowding prior to the treatment, upper and lower lip protrusion at the end of the treatment, the amount of the growth at the end of the treatment and the degree of retroinclination of the lower incisors at the start of the treatment, correlate with the increase in mandibular incisor irregularity during the postretention phase. Often mentioned factors such as upper incisor inclination, overbite, arch length, overjet, intermolar and intercanine width, mandibular rotation and lip thickness and length were not found not to be correlated with the post-retention incisor crowding.

These result should be considered with caution since they only describe the patients studied and the specific treatment mechanics performed. The present study suggests that treatment mechanics may play a significant role in the stability of the mandibular incisor alignment following orthodontic treatment. 


\section{REFERENCES}

1. Moorrees, C.F.A.: The dentition of the growing child. Cambridge, Mass., Harvard University Press.1959.

2. Foster, T.D., Hamilton, M.C., and LaVelle, C.L.B.: A study of dental arch crowding in four age-groups. Dent. Practit. 21:9-12, 1970.

3. Lundstrom, A.: A study of correlation between mandibular growth direction and changes in incisor inclination, overjet, overbite and crowding. Trans. Eur. Orthod. Soc. 131-140, 1975.

4. Sinclair, P.M., Little, R.M.: Maturation of untreated normal occlusions. Am. J. Orthod. 83:114-123, 1983.

5. Morrees, C.F.A., Gron, A., Lebret, L.M., Yen,P.K.J., Fronlich, F.J.: Growth studies of the dentition: A review. Am. J. Orthod. 55: $600-616$

6. Barrow, G.V., and White, J.R.: Developmental changes of the maxillary and mandibular dental arches. Angle orthod. 22:4145,1952 .

7. Little, R.M., Wallen, T.R., and Riedel R.A.: stability and relapse of mandibular anterior alignment - first premolar extraction cases treated by traditional edgewise orthodontics. Am. J. Orthod. 80:349-365, 1981 .

8. Glenn, G., Sinclair, P.M., Alexander, R.G.: Nonextraction orthodontic therapy: Posttreatment and skeletal stability. Am. $J$. Orthod. $92: 321-328,1987$.

9. Uhde, M.D., Sadowsky, C., BeGole, E.A.: Long-term stability of 
dental relationships after orthodontic treatment. Angle orthod. $53: 240-252$, 1983 .

10. Fastlicht.J.: Crowding of mandibular incisors. Am. J. Orthod. $58: 156-163,1970$.

11. Gardner, S.D., and Chaconas, S.J.: Posttreatment and postretention changes following orthodontic therapy. Angle orthod. $46: 151-161,1976$.

12. Shapiro, P.A.: Mandibular dental arch form and dimension. Am. J. Orthod. $66: 58-70,1974$.

13. Simons, M.E., Joondeph, D.R.: Change in overbite: A ten-year postretention study. Am. J. Orthod. 64:349-367, 1973.

14. Hernandez, J. L.: Mandibular bicanine width relative to overbite. Am. J. Orhod. 56:455-467, 1969.

15. Bjork, A., and Skieller, V.: Facial development and tooth eruption. An implant study at the age of puberty. Am. J. Orthod. $62: 339-383,1972$.

16. Sinclair, P.M., Little, R.M.: Dentofacial maturation of untreated normals. Am. J. Orthod. 88:146-156, 1985.

17. Sanin, C., Savara, B.C.: Factors that affect the alignment of the mandibular incisors: A longitudinal study. Am. J. Orthod. $64: 248-257$, 1973 .

18. Norderval., K., Wisth, P. J., Boe, O. E.: Mandibular anterior crowding in relation to tooth size and craniofacial morphology. Scand. J. Dent. Res. 83:267-273,1975.

19. Richardson, M.E.: Late lower arch crowding, the role of facial morphology. Angle Orthod. 56:244-254,1986. 
20. Schudy, G.F.: Posttreatment craniofacial growth: Its implications in orthodontic treatment. Am J. Orthod. 65:39-57, 1974 .

21. Keene, A., Engel, G.: The mandibular dental arch, part IV: prediction and prevention of lower anterior relapse, Angle Orthod. $49: 173-180,1979$.

22. Burstone, C. J., Hickman, J.: University of Connecticut Health Center, Monograph. Denver growth study data. 1968 .

23. Miethke, R., Behm-Menthel, A.: Correlation between lower incisor crowding and lower incisor position and lateral craniofacial morphology. Am. J. Orthod. Dentofac. Orthop. 94:231239,1988

24. El-Mangoury, N.H.: Orthodontic relapse in subjects with varying degrees of anteroposterior and vertical dysplasia. Am. J. Orthod. $75: 548-561,1979$.

25. Huggins, D.G., Birch,R.H.: A cephalometric investigation of stability of upper incisor following their retraction. $A m$. $J$. Orthod. 50:852-856, 1964 .

26. Shields, T.E., Little, R.M., Chapko, M.K.: stability and relapse of mandibular anterior alignment: A cephalometric appraisal of first-premolar-extraction cases treated by traditional edgewise orthodontics. Am. J. Orthod. 87:27-38, 1985.

27. Schulhof, R.J., Allegw R.W., Walters, R.D., Dreskin, M.: The mandibular dental arch: part I, lower incisor position. Angle Orthod. $\quad 47: 280-287,1977$.

28. Weinstein, S., Haack, D.C., Morris, N.Y., Snyder, B.B., 
Attaway, H.E.: On an equilibrium theory of tooth position. Angle Orthod. $33: 1-26,1963$.

29. Proffit, W.R.: Equilibrium theory revisied. Angle orthod. $48: 175-186,1978$.

30. Luffingham, J.K.: Lip and cheek pressure exerted upon teeth in three adult groups with different occlusions. Archs. Oral. Biol. $14: 337-350,1969$.

31. Thuer, U., Ingervall, B.: Pressure from the lips on the teeth and malocclusion. Am. J. Orthod. Dentofac. Orthop. 90:234-242,1990. 32. Riedel, R. A.: An analysis of dentofacial relationships. Am. J. Orthod. 43:103-119,1957.

33. Winders, R.V.: An electronic technique to measure the forces exerted on the dentition by perioral and lingual musculature. Am. J. Orthod. 42:645-657, 1956.

34. Subtenly, J.D.: The soft tissue profile, growth, and treatment changes. Angle Orthod. 31:105-122, 1961.

35. Subtenly, J.D.: A longitudinal study of soft tissue facial structures and their profile characteristics defined in relation to underlying skeletal structures. Am. J. Orthod. 45:481-507, 1959. 36. Burstone, C. : The integumental profile. Am. J. Orthod. 44:125,1958 .

37. Burstone, C.J.: Lip posture and its significance in treatment planning. Am. J. Orthod. 53:262-332, 1967.

38. Lenard, J. A.: A longitudinal study of integumental profile growth increments of normal males and females from eihgt to eighteen years of age. Thesis, University of Connecticut. 1984. 
39. Nanda, R.S., Meng, H., Kapila, S., Goorhuis, J.: Growth changes in the soft tissue facial profile. Angle Orthod. 60:177-190, 1990. 40. Rudee, D.A.: Proportional profile changes concurrent with orthodontic therapy. Am. J. Orthod. 50:421-434, 1964 .

41. Bloom, L.A.: Perioral profile changes in orthodontic treatment. Am. J. Orthod. 47:371-379, 1961 .

42. Hershey, H. G.: Incisor tooth retraction and subsequent profile change in postadolescent female patients. Am. J. Orthod. 61:4554,1972 .

43. Oliver, B.M.: The influence of lip thickness and strain on upper lip response to incisor retraction. Am. J. Orthod. 82:141149,1982 .

44. Anderson, J. P.., Joondeph, D.R., and Turpin, D.L.: A cephalometric study of the profile changes in orthodontically treated cases ten years out of retention. Angle orthod. 43:324-336, 1973 .

45. Rains, M.D., and Nanda, R.: Soft-tissue changes associated with maxillary incisor retraction. Am. J. Orthod. 81:481-488, 1982.

46. Marcotte, M. R.: The use of occlusogram in planning orthodontic treatment. Am. J. Orthod. 69:655-667,1976.

47. Little, R. M.: The irregularity index: A quantitative score of mandibular anterior alignment. Am. J. Orthod. 68:554-563,1975. 48. Nance, H.N.: The limitations of orthodontic treatment. Am. J. Orthod. 33:177-223, 1947 .

49. Lombardi, A.R.: Mandibular incisor crowding in completed cases. Am. J. Orthod. 61:374-383,1972. 
50. Magill, J.M.: Changes in the anterior overbite relationship following orthodontic treatment in extraction cases. Am. J. orthod. $46: 755-788,1960$.

51. Angelle, P. L.: A cephalometric study of the soft tissue changes during and after orthodontic treatment. Trans. Eur. Orthod. SOC. $49: 267-280,1973$.

52. Rickettes, R. M.: The influence of orthodontic treatment on facial growth and development. Angle orthod. 30:103-133,1960. 53. Roos, N: Soft-tissue profile changes in Class II treatment. Am. J. Orthod. 72:165-175, 1977.

54. Burstone, C. J.: Deep overbite correction by intrusion. Am. J. Orthod. $72: 437-436,1977$.

55. Solow, B.: The pattern of craniofacial associations. Acta. Odont. Scand. 24 :Suppl. 46, 1966. 
Table I. Sample Characteristics

\begin{tabular}{lcr}
\hline & Mean(years) & Range (years) \\
\hline & & \\
Pre-treatment age & 12.91 & $9.08-23.17$ \\
Post-treatment age & 14.86 & $11.83-24.72$ \\
Post-retention period & 1.11 & $1.05-1.75$ \\
& & Pumber \\
\cline { 2 - 3 } & & Percent \\
\hline
\end{tabular}

Ireatment Procedure

Extraction

Nonextraction

$\underline{\operatorname{sex}}$

Male

Female
16

18

47.1

52.9

Angle's Dental Classification

Class I

Class II

Total
11

23

34
38.2

61.8

13
21

32.4

67.6

100.0 
Table II. Dental, mandibular incisor, and maxillary incisor changes at pretreatment(T1), at the end of treatment(T2) and post-retention(T3)

\begin{tabular}{|c|c|c|c|c|c|c|}
\hline & \multicolumn{2}{|c|}{ Pretreatment } & \multirow{2}{*}{$\begin{array}{r}\text { T1 } \\
\text { Mean } \\
\end{array}$} & \multirow{2}{*}{$\begin{array}{r}-\mathrm{T} 2 \\
\mathrm{SD} \\
\end{array}$} & \multicolumn{2}{|c|}{$\mathrm{T} 2-\mathrm{T} 3$} \\
\hline & Mean & SD & & & Mean & SD \\
\hline \multicolumn{7}{|l|}{ Dental Measurements } \\
\hline Incisor Irregularity & 6.97 & 4.32 & -5.30 & $4.15 \star \star+$ & 1.69 & $1.24 \star \star$ \\
\hline Intermolar width & 39.06 & 2.43 & -0.99 & $1.90^{\star \star}++$ & 0.09 & 0.86 \\
\hline Intercanine width & 25.30 & 2.47 & 0.69 & $1.85^{\star}$ & -0.39 & $0.76^{\star \star}$ \\
\hline Arch length & 59.37 & 4.15 & -4.71 & $6.06^{\star \star++}$ & -1.08 & $1.58^{\star \star \#}$ \\
\hline \multicolumn{7}{|l|}{ Mandibular Incisor } \\
\hline $\mathrm{L} 1-\mathrm{CEH}(\mathrm{O})$ & 62.57 & 6.61 & 1.62 & 7.48 & 0.32 & 4.15 \\
\hline L1-MP (0) & 91.08 & 7.38 & -1.04 & $7.50^{++}$ & 0.73 & 4.40 \\
\hline $\mathrm{L} 1-\mathrm{OP}(0)$ & 76.17 & 6.65 & 0.91 & $7.29^{+}$ & 0.11 & 4.59 \\
\hline L6-OP $(0)$ & 84.43 & 5.31 & 2.81 & $5.18^{\star}$ & -0.79 & 4.89 \\
\hline Ii-CFH (mm, y-coordinate) & 69.74 & 4.73 & -1.81 & $1.96^{\star \star+\wedge \#}$ & -0.81 & $0.87^{\star \star}$ \\
\hline I i-CFH (mm, $x$-coordinate) & 71.15 & 5.98 & -0.68 & $2.65^{++}$ & 0.21 & 1.17 \\
\hline Ii-OP (mm, y"-coordinate) & 3.38 & 1.70 & 1.36 & $10.66^{\star \star \wedge} \#$ & 0.81 & $0.82^{\star \star \wedge}$ \\
\hline Ii-OP (mm, $x "$-coordinate) & 72.57 & 5.52 & -1.10 & $2.82^{\star}++$ & 0.00 & 1.22 \\
\hline \multicolumn{7}{|l|}{ Maxillary Incisor } \\
\hline $\mathrm{U} 1-\mathrm{CFH}\left(0^{\circ}\right)$ & 110.22 & 6.80 & -1.10 & 7.22 & 2.27 & $5.00^{\star}$ \\
\hline $\mathrm{U} 1-\mathrm{NF}(0)$ & 110.64 & 7.07 & -0.76 & 7.07 & 1.72 & $4.71^{\star}$ \\
\hline $\mathrm{U} 1-\mathrm{LI}(0)$ & 132.19 & 11.03 & 2.72 & $12.14^{+}$ & -1.94 & 7.36 \\
\hline Is-Ii (CFH, mm, overjet) & 4.14 & 1.70 & -1.14 & $1.61^{\star \star}$ & 0.54 & $1.10^{\star \star}$ \\
\hline Is-Ii (pCFH, mm, overbite) & 3.70 & 1.62 & -0.79 & $1.75^{\star \star}$ & 0.02 & 1.35 \\
\hline Is-CFH (mm, y-coordinate) & 73.36 & 4.70 & 1.69 & $2.48^{\star \star \wedge}$ & 1.03 & $1.55^{\star \star}$ \\
\hline Is-CFH (mm, $\mathrm{x}$-coordinate) & 75.28 & 6.07 & -0.04 & $2.84^{+}$ & 2.04 & $2.20 \star \star \wedge \wedge$ \\
\hline Is-NF (mm, $y^{\prime}$-coordinate) & 29.03 & 2.60 & 1.14 & $1.39 \star \star+$ & 1.66 & $1.40^{\star \star}$ \\
\hline Is-NF (mm, $x^{\prime}$-coordinate) & 75.34 & 5.18 & -0.56 & 2.68 & 0.65 & $1.38^{\star \star}$ \\
\hline
\end{tabular}

$\star p<0.05, \star \star p<0.01$ of paired t-test with T1 and T2,T2 and T3 $x$-coordinate represents anterior $(+)$ and posterior $(-)$ changes $y$-coordinate represents extrusive(t) and intrusive(-) changes

+ indicates statistical difference between extraction and nonextraction group ( $p<0.05,++p<0.01)$

$\wedge$ indicates statistical difference between male and female group (^ $p<0.05$. ^^ $p<0.01$ )

\# indicates statistical difference between Angle's dental classification Class I and Class II (\#p<0.05, \# $p<0.01$ ) 
Table III. Soft tissue, occlusal plane, mandibular rotation, and growth changes at pretreatment (T1), at the end of treatment (T2) and postretention (T3)

\begin{tabular}{|c|c|c|c|c|c|c|}
\hline & \multicolumn{2}{|c|}{ Pretreatment } & \multicolumn{2}{|c|}{$\mathrm{T} 1-\mathrm{T} 2$} & \multicolumn{2}{|c|}{$\mathrm{T} 2-\mathrm{T} 3$} \\
\hline & Mean & SD & Mean & $S D$ & Mean & SD \\
\hline \multicolumn{7}{|l|}{ Seft Tissue } \\
\hline Ls $\left(\mathrm{Sn}-\mathrm{Pg} \mathrm{g}^{\prime}, \mathrm{mm}\right)$ & 3.31 & 2.74 & -1.20 & $1.45^{\star \star}$ & -0.28 & 1.57 \\
\hline $\mathrm{Li}\left(\mathrm{Sn}-\mathrm{Pg}{ }^{\prime}, \mathrm{mm}\right)$ & 3.02 & 2.68 & -1.22 & $1.49^{\star \star++}$ & -0.49 & $1.37^{\star}$ \\
\hline Nasolabial angle & 109.16 & 12.04 & 3.55 & $4.87^{\star \star}$ & -0.37 & $4.95^{\#}$ \\
\hline Upper lip thickness (mm) & 12.99 & 2.52 & 0.70 & $1.99^{\star}+$ & -0.08 & 1.92 \\
\hline Lower lip thickness (mm) & 14.77 & 2.21 & -0.28 & $1.89+$ & -0.36 & 1.47 \\
\hline Upper lip length (mm) & 21.10 & 2.71 & 0.74 & $1.65^{\star++}$ & -0.35 & 1.11 \\
\hline Lower lip length (mm) & 16.66 & 1.97 & 1.03 & $1.64 \star \star$ & 0.58 & $1.37^{\star}$ \\
\hline Lip to tooth contact (mm) & 2) 5.39 & 2.25 & -0.99 & $2.16^{\star++}$ & -0.48 & 1.80 \\
\hline \multicolumn{7}{|l|}{ ecclusal plane } \\
\hline$A-B(O P, m m)$ & 2.04 & 2.60 & 0.24 & 2.34 & 0.13 & $2.17^{+}$ \\
\hline $\mathrm{OP}-\mathrm{CEH}(\mathrm{O})$ & 13.69 & 4.28 & -0.71 & 3.00 & -0.17 & 3.12 \\
\hline OP change ( $\left.{ }^{\circ}\right)$ & & & -0.97 & 2.93 & 0.23 & $2.54^{+}$ \\
\hline \multicolumn{7}{|l|}{ Mandibular Rotation } \\
\hline$Y-\operatorname{axis}(0)$ & 60.18 & 3.48 & 0.06 & 1.11 & -0.50 & $1.05^{\star \star}$ \\
\hline Gonial angle & 125.06 & 6.12 & -0.93 & $1.80 \star \star$ & -1.06 & $2.06^{\star \star}$ \\
\hline \multicolumn{7}{|l|}{ Growth } \\
\hline $\operatorname{Ar}-\mathrm{Pg}(\mathrm{mm})$ & 107.17 & 6.17 & 4.18 & $3.67^{\star \star \wedge}$ & 2.37 & $2.09^{\star \star}$ \\
\hline ANS-Me (mm) & 67.87 & 5.70 & 2.33 & $2.81^{\star \star \wedge \wedge}$ & 1.33 & $1.76^{\star \star}$ \\
\hline
\end{tabular}

$\star p<0.05, \star \star p<0.01$ of paired t-test with T1 and T2,T2 and T3

+ indicates statistical difference between extraction and nonextraction group $(+p<0.05,++p<0.01)$

$\wedge$ indicates statistical difference between male and female group (^ $p<0.05$. ^^ $p<0.01$ )

\# indicates statistical difference between Angle's dental classification Class I and Class II (\#p<0.05, \#p<0.01) 
Table IV. Correlation between treatment effects(T1-T2) and the change at post-retention (T2-T3)

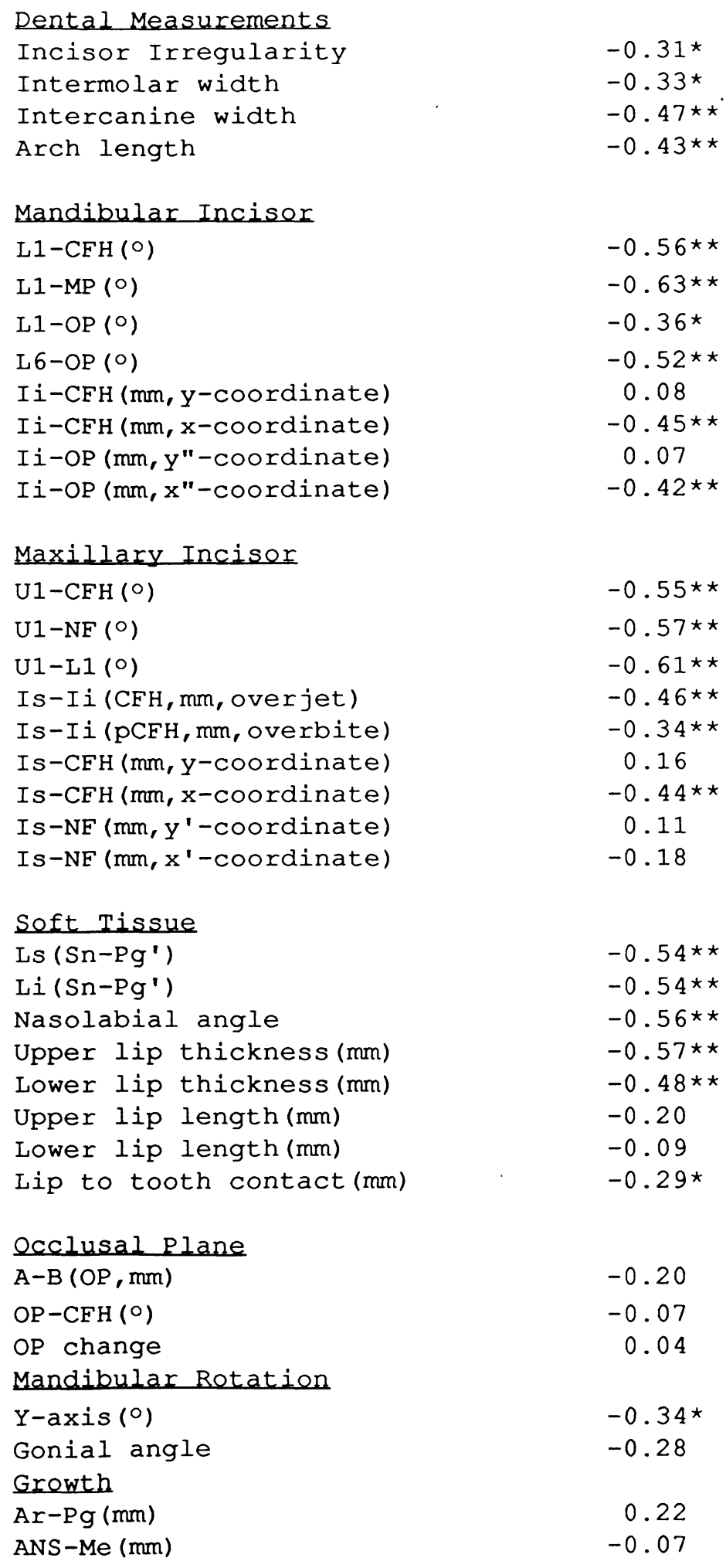

Mandibular Rotation

$Y$-axis ( $\left.{ }^{\circ}\right)$

Gonial angle

$-0.34 \star$

Growth

Ar-Pg (mm)

$-0.28$

ANS-Me (mm)

0.22

$-0.07$

$\star p<0.05, * \star p<0.01$ of Pearson correlation coefficient 
Table V. Changes of incisor irregularity correlation coefficient with pretreatment variables, absolute, positive and negative changes at T1-T2 and T2-T3 (dental, maxillary and mandibular measurements)

\begin{tabular}{|c|c|c|c|c|c|c|c|}
\hline \multirow[b]{2}{*}{ Dental Measurements } & \multirow[t]{2}{*}{ Pretreatemnt } & \multirow{2}{*}{$\begin{array}{c}\text { Absolute } \\
\mathrm{T} 1-\mathrm{T} 2\end{array}$} & \multirow{2}{*}{$\begin{array}{r}\text { Change } \\
\text { T2-T3 } \\
\end{array}$} & \multicolumn{2}{|c|}{ Positive change } & \multicolumn{2}{|c|}{ Negative change } \\
\hline & & & & & $T 2-T 3$ & & $\mathrm{~T} 2-\mathrm{T} 3$ \\
\hline Incisor Irregularity & 0.27 & $0.30 \star$ & & & & $0.30 *$ & \\
\hline Intermolar width & -0.01 & 0.03 & 0.25 & 0.34 & 0.21 & 0.15 & $-0.40 *$ \\
\hline Intercanine width & -0.10 & -0.04 & 0.13 & -0.12 & 0.28 & 0.04 & -0.09 \\
\hline Arch length & -0.19 & -0.21 & -0.28 & -0.20 & 0.23 & 0.23 & -0.20 \\
\hline \multicolumn{8}{|l|}{ Mandibular Inciser } \\
\hline $1-\mathrm{CFH}(0)$ & 0.39 & -0.17 & $-0.36 \star$ & -0.24 & $-0.39 \star$ & 0.03 & 0.29 \\
\hline $1-M P(0)$ & -0.30 & -0.12 & $-0.33 \star$ & 0.28 & -0.18 & $0.38 \star$ & $0.40 *$ \\
\hline $1-O P(0)$ & 0.31 & -0.17 & -0.18 & $-0.41 *$ & -0.41 & -0.08 & -0.17 \\
\hline 6-OP (0) & -0.09 & -0.20 & -0.12 & -0.14 & 0.17 & 0.42 & 0.27 \\
\hline Ii-CFH (mm, Y coordinate) & -0.87 & 0.18 & $-0.37 \star$ & 0.35 & 0.35 & 0.27 & -0.38 \\
\hline Ji-CEH (mm, $x$ coordinate) & -0.13 & $0.32 \star$ & -0.16 & -0.51 & 0.08 & $0.36 \star$ & 0.19 \\
\hline Ii-OP (mm, y"coordinate) & -0.19 & 0.07 & $0.33 \star$ & -0.23 & $0.41 *$ & -0.18 & 0.81 \\
\hline Ii-OF (mm, $x "$ coordinate) & -0.14 & $0.32 \star$ & -0.10 & -0.48 & 0.03 & 0.35 & 0.08 \\
\hline \multicolumn{8}{|l|}{ Maxillary Incisor } \\
\hline $1-\mathrm{CFH}(0)$ & -0.02 & -0.06 & 0.01 & -0.21 & 0.08 & -0.15 & 0.24 \\
\hline $\begin{array}{l}1-N F(0) \\
1-1(0)\end{array}$ & 0.02 & -0.08 & -0.02 & -0.21 & -0.05 & -0.06 & 0.06 \\
\hline Is-Ii (CFH, mm, overiet) & 0.25 & -0.03 & -0.07 & -0.04 & -0.10 & -0.08 & 0.12 \\
\hline Is-II (CEH, mm, overjet) & 0.24 & 0.20 & 0.22 & $-0.79 \star \star$ & $=0.24$ & -0.24 & 0.07 \\
\hline Is-Ii (pCFH, mm, overbite) & 0.19 & 0.01 & $0.31 \star$ & -0.11 & 0.14 & 0.10 & -0.41 \\
\hline Is-CFH (mm, y coordinate) & -0.08 & 0.21 & 0.19 & 0.30 & 0.13 & -0.01 & 0.41 \\
\hline Is-CFH ( $\mathrm{mm}, \mathrm{x}$ coordinate) & 0.01 & 0.03 & 0.05 & -0.08 & 0.02 & -0.20 & -0.64 \\
\hline Is-NF (mm, $y^{\prime}$ coordonate) & -0.34 & 0.14 & 0.01 & 0.10 & 0.00 & -0.36 & 1.00 \\
\hline Is-NF (mm, $x^{\prime}$ coordinate) & 0.03 & -0.14 & -0.20 & 0.05 & 0.30 & -0.14 & -0.18 \\
\hline
\end{tabular}

$\star p<0.05, * \star p<0.01$ of Pearson correlation coefficient 
Table VI. Changes of incisor irregularity correlation coefficient with pretreatment variables, absolute, positive and negative changes at T1-T2 and T2-T3(soft tissue, occlusal plane, mandibular rotation and growth measurements)

\begin{tabular}{|c|c|c|c|c|c|c|c|}
\hline & \multirow[t]{2}{*}{ Pretreatemnt } & \multirow{2}{*}{$\begin{array}{c}\text { Absolute } \\
\text { T1-T2 }\end{array}$} & \multirow{2}{*}{$\begin{array}{c}\text { Change } \\
\text { T2-T3 }\end{array}$} & \multicolumn{2}{|c|}{ Positive change } & \multicolumn{2}{|c|}{ Negative change } \\
\hline & & & & $\mathrm{T} 1-\mathrm{T} 2$ & $\mathrm{~T} 2-\mathrm{T} 3$ & $\mathrm{~T} 1-\mathrm{T} 2$ & $\mathrm{~T} 2-\mathrm{T} 3$ \\
\hline \multicolumn{8}{|l|}{ Soft Tissue } \\
\hline $\mathrm{Pls}\left(\mathrm{Sn}-\mathrm{Pg}{ }^{\prime}\right)$ & -0.11 & -0.17 & -0.23 & $-0.68 *$ & -0.21 & 0.07 & 0.14 \\
\hline Pli (Sn-Pg') & -0.28 & -0.25 & 0.05 & $-0.66^{\star}$ & 0.35 & 0.15 & -0.01 \\
\hline Nasolabial angle & 0.06 & 0.15 & -0.001 & $0.33 \star$ & -0.02 & 0.25 & -0.06 \\
\hline Upper lip thickness (mm) & n) 0.04 & 0.04 & 0.11 & 0.14 & $0.46 \star$ & 0.18 & 0.19 \\
\hline Lower lip thickness (mm) & 0.22 & -0.03 & -0.06 & -0.21 & 0.17 & -0.15 & 0.08 \\
\hline Lower lip length(mm) & -0.24 & 0.23 & -0.004 & 0.37 & 0.27 & 0.002 & -0.03 \\
\hline Upper lip length (mm) & 0.03 & -0.07 & -0.13 & -0.06 & -0.18 & $0.58 \star$ & 0.33 \\
\hline Lip contact (mm) & 0.16 & 0.12 & 0.06 & -0.20 & 0.12 & -0.16 & -0.25 \\
\hline \multicolumn{8}{|l|}{ occlusal Plane } \\
\hline$A-B(O P, m m)$ & -0.001 & 0.03 & 0.19 & -0.01 & $0.41 \star$ & -0.07 & 0.34 \\
\hline $\begin{array}{l}\text { OP-CFH (O) } \\
\text { OP change }\end{array}$ & -0.13 & 0.08 & -0.10 & -0.03 & 0.08 & -0.27 & 0.30 \\
\hline & & 0.11 & 0.10 & 0.07 & $0.40 \star$ & 0.11 & 0.10 \\
\hline \multicolumn{8}{|l|}{ Mandibular Rotation } \\
\hline Y-axis $(0)$ & -0.19 & -0.28 & -0.11 & -0.20 & -0.13 & 0.41 & 0.11 \\
\hline Gonial angle & 0.16 & 0.08 & 0.002 & -0.28 & 0.04 & -0.25 & -0.07 \\
\hline \multicolumn{8}{|l|}{ Growth } \\
\hline $\mathrm{Ar}-\mathrm{Pg}(\mathrm{mm})$ & -0.02 & 0.01 & $0.39 \star$ & 0.20 & $0.45 * \star$ & 0.09 & -0.14 \\
\hline ANS-Me (mm) & -0.20 & -0.05 & $0.35 \star$ & 0.07 & $0.43^{\star}$ & -0.20 & $0.78 \star$ \\
\hline
\end{tabular}

$\star p<0.05, * \star p<0.01$ of Pearson correlation coefficient 


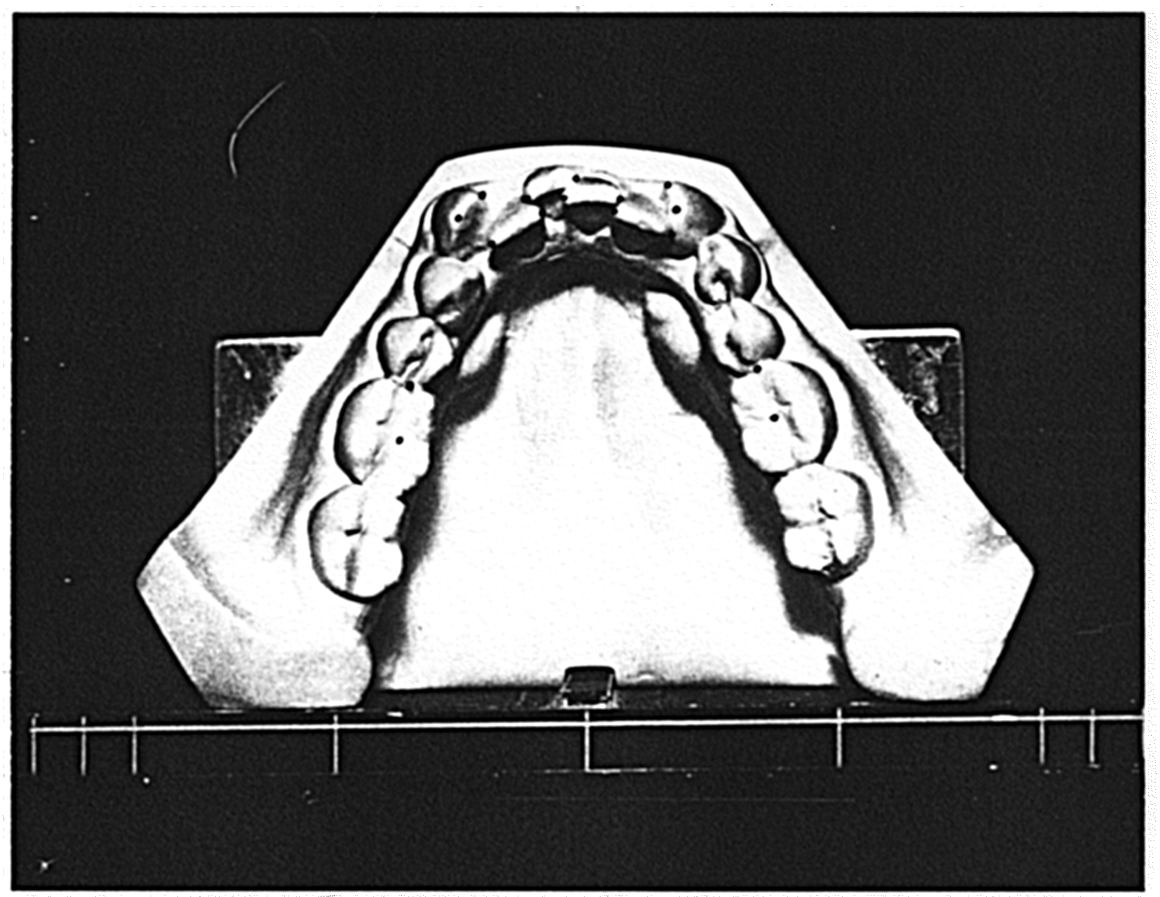

Fig.1 Landmarks for dental measurements 


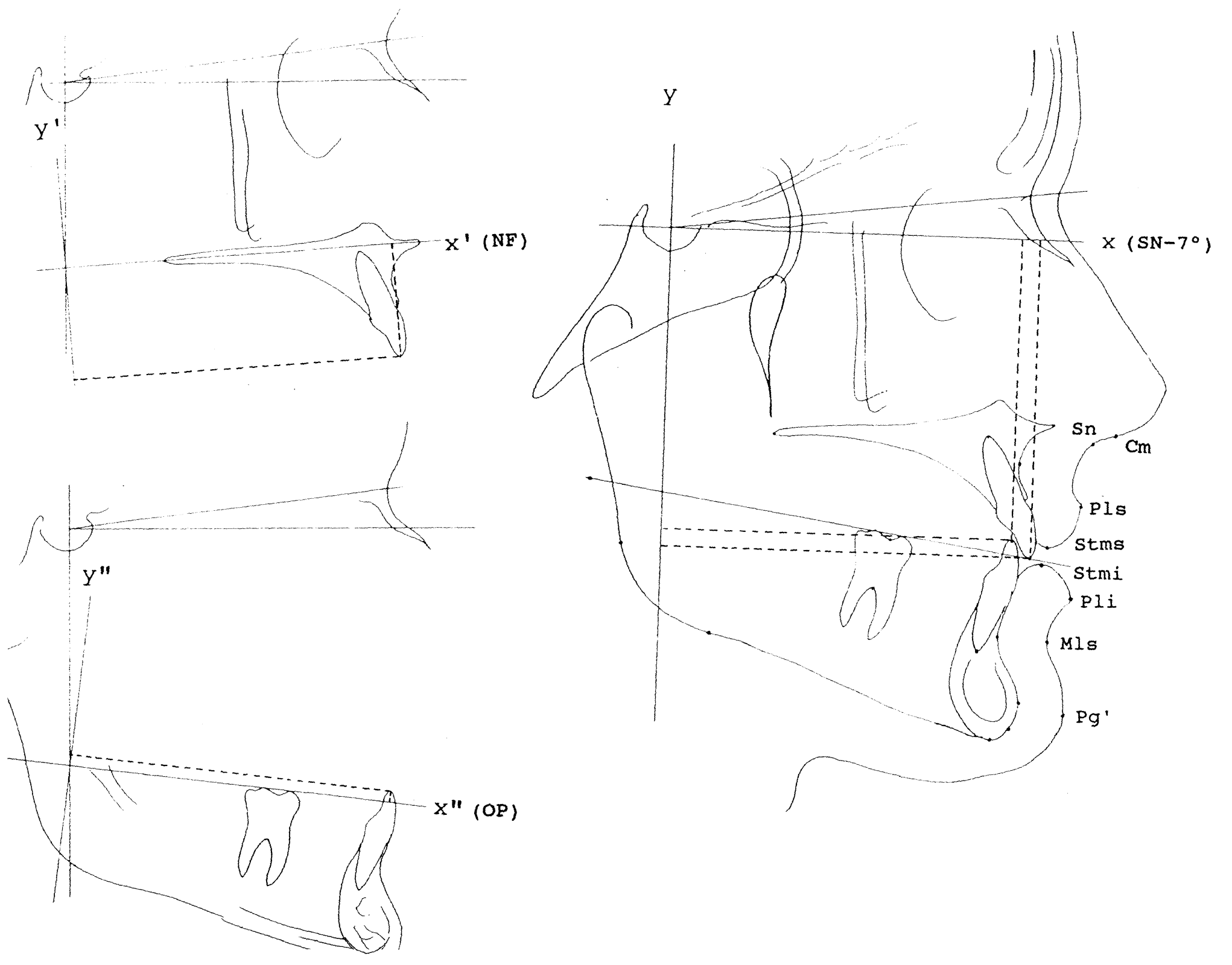

Fig. 2. The hard and soft tissue landmarks along with horizontal and vertical reference planes in anterior cranial base, maxillary and mandibular superimposition. 